\title{
RIVER WARBLER (LOCUSTELLA FLUVIATILIS) AT GAMBELL, ALASKA: FIRST RECORD FOR NORTH AMERICA
}

PAUL E. LEHMAN, 11192 Portobelo Drive, San Diego, California 92124;

lehman.paul@verizon.net

During the late afternoon on 7 October 2017 at Gambell, St. Lawrence Island, Alaska, local residents and bird photographers Sue Bryer and Clarence Irrigoo Jr., as well as visiting birder Ebbe Banstorp, were in the village's "near boneyard." The several boneyards at Gambell are midden sites that support a relatively lush growth of two species of Artemisia (wormwood), which provides food and cover for migrating landbirds. At the east end of the near boneyard, Bryer flushed a small passerine, which she was able to photograph only in flight. Shortly thereafter, visiting birder Monte M. Taylor also obtained brief views of the bird in flight. Upon reviewing Bryer's photographs, Taylor saw enough detail to radio me that I should quickly come over to see a bird resembling a Blyth's Reed Warbler (Acrocephalus dumetorum), an Asian species previously documented at Gambell twice in fall (Lehman and Ake 2011).

I soon joined the group and was quickly able to flush the bird twice again. It appeared to be a medium-sized Old World warbler with very uniform dull olive-graybrown upperparts, a somewhat rounded tail, weak flight, and skulky behavior. After the third flush of the bird, I was able to observe it on the ground briefly before it ran into cover. I noted that it had bright flesh-pinkish legs and feet and that it lacked a noticeable supercilium, instead showing a pale eye-ring that was thin yet distinct. These characters suggested that it was a species of Locustella warbler previously unrecorded in North America.

Over the next several hours, we followed the bird around the near boneyard. The bird's behavior throughout was remarkably consistent, flushing at close range and flying short distances before landing where it could sometimes be seen on the ground before scurrying back into cover. No vocalizations were heard. The bird's features included

- Upperparts (including the wings) mostly uniform in color, appearing, in neutral lighting, to be a dull light-to-medium brownish tinged with dull olive, but they sometimes appeared to be warm brown when viewed in brighter lighting (Figures 1-4).

- A fairly distinct but narrow whitish eye-ring on an otherwise blank-looking face that on several occasions showed a pale, very weak supraloral stripe between the base of the bill and the eye or simply above the eye. When the bird could be seen well, some fine dusky streaks were visible on the auriculars (Figures 1-4).

- A thin and pointed bill of medium proportions, with the upper mandible mostly dark but much of the lower mandible and the cutting edge of the upper mandible distinctly pale-either dull yellowish or yellowish flesh (Figures 1, 2, and 4).

- Underparts pale, mostly dirty whitish, lacking yellowish or strong buff, but with the breast and lower throat showing extensive blurry dull olive or brownish-olive streaking (Figures 1 and 2). The sides of the breast and especially the flanks were washed with olive brown or grayish brown.

- Bright flesh-pink legs and feet (Figures 1-4).

- Upper side of the tail the same uniform olive brown as the remainder of the upperparts; the tail appeared rather broad, of short to medium length, and clearly rounded to weakly wedge-shaped at the tip, as the rectrices were distinctly graduated (Figures 1 and 4).

- Very long undertail coverts that extended approximately $90 \%$ of the distance 


\section{NOTES}

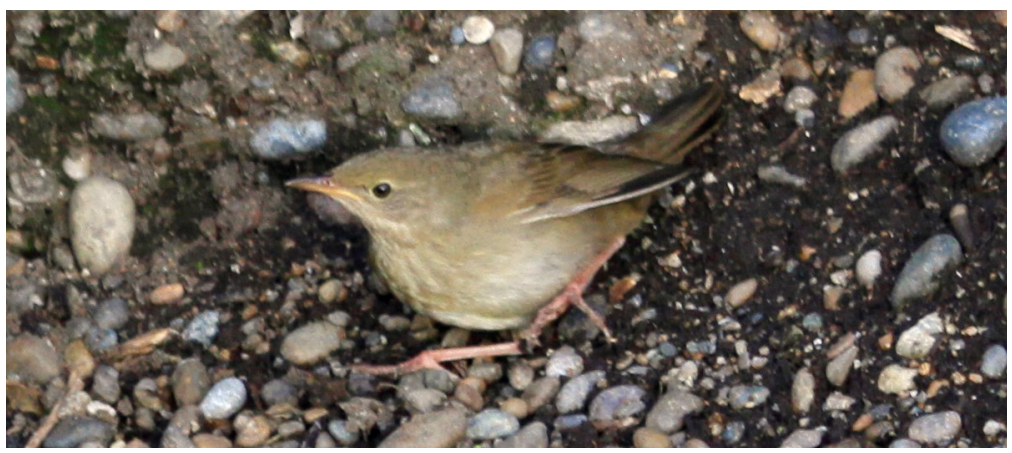

Figure 1. This view of the River Warbler at Gambell on 7 October 2017, taken in neutral, flat lighting, captures many of the features of the bird: a mostly plain face with a thin pale circular eye-ring, blurry broad olive-brown streaks on the lower throat and breast, mostly uniform dull olive-gray-brown upperparts from crown to tail, a broad and strongly rounded tail, a mostly dull yellowish or flesh-yellow lower mandible and cutting edge to upper mandible, and bright fleshy legs and feet. Also note the pale edge to the outermost primary - a character of a number of the Locustella warblers.

Photo by Clarence Irrigoo Jr.

to the tip, light brownish with broad and somewhat irregular off-white tips that produced a slightly messy pattern of alternating broad brown and off-white bars (Figures 3 and 4).

- Outer primaries that in photos appeared somewhat curved (Figure 4).

These characteristics pointed to one of three primarily European/west Asian species of Locustella, the Grasshopper (L. naevia), Savi's (L. luscinioides), or River Warbler (L. fluviatilis), none previously recorded in North America. Species that could be eliminated from consideration in the field included

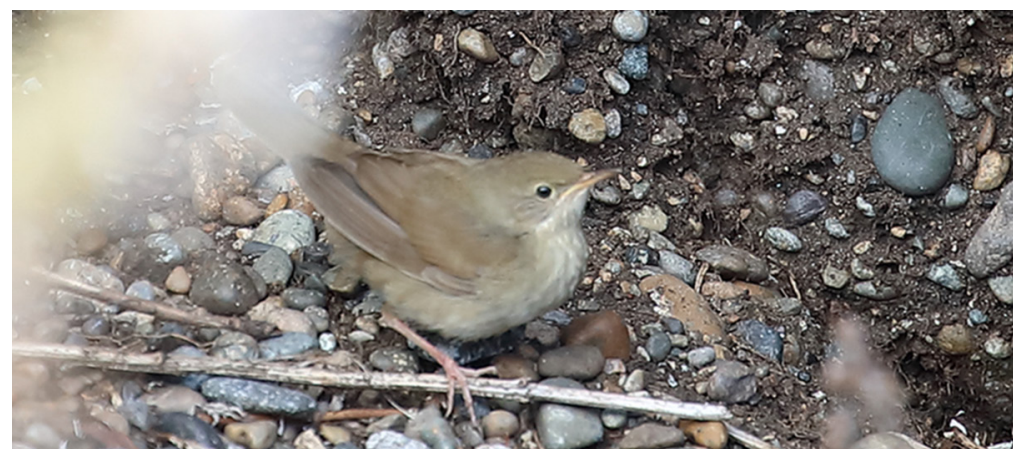

Figure 2. This photo was taken in slightly brighter light than was Figure 1, and the browns of the wing coverts and scapulars appear somewhat warmer than when viewed under more neutral lighting. 


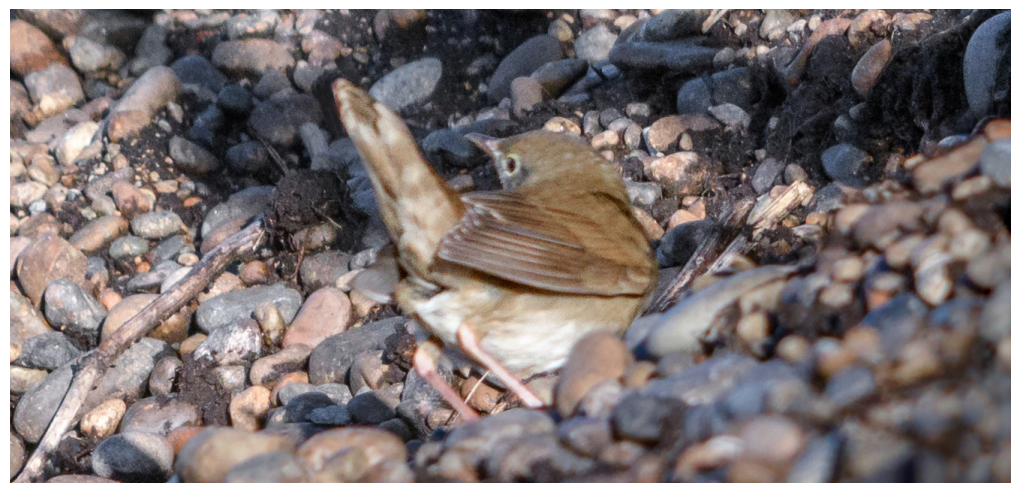

Figure 3. This photo shows the River Warbler's broad and graduated tail feathers and brownish undertail coverts broadly tipped in off-white, resulting in a slightly messy pattern of alternating bars. In the River Warbler the undertail coverts extend some $80-90 \%$ of the distance to the tip of the tail.

Photo by Sue Bryer

\section{Acrocephalus}

- Blyth's Reed Warbler has a narrow but distinct supercilium in front of and over the eye rather than an eye-ring; it lacks breast streaks, has shorter and unmarked undertail coverts, and has duller legs; the Eurasian Reed (A. scirpaceus) and Marsh (A. palustris) Warblers, unrecorded in North America, are

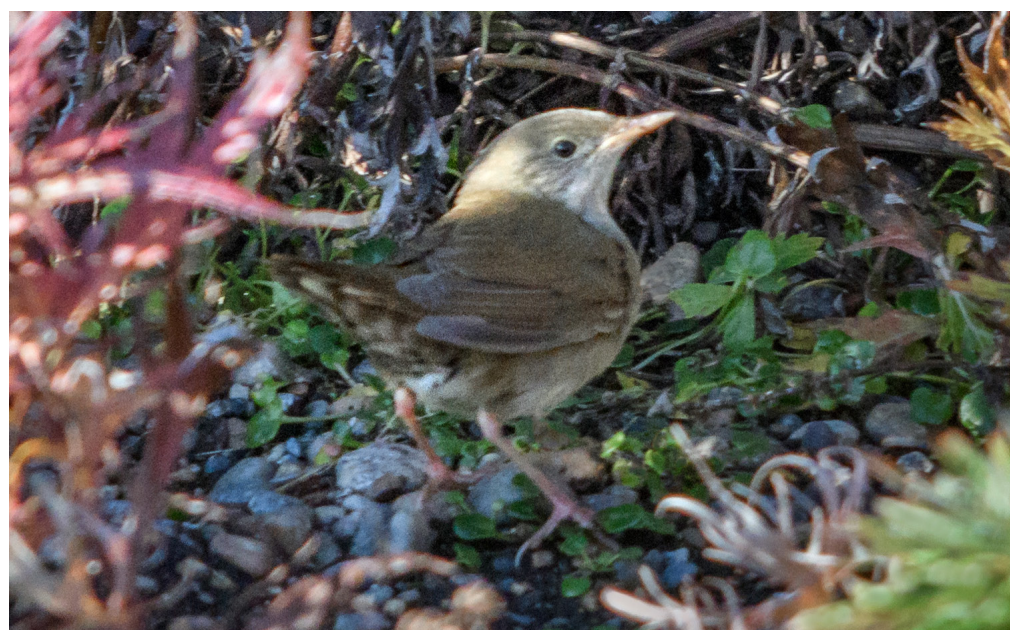

Figure 4. This photo was taken partly in bright, direct light, which tends to accentuate the grayish tones to the head and the warmer brown tones to some of the upperparts and wing-coverts. This photo also shows the color pattern and relative length of the undertail coverts. Note the fine, faint dusky streaks to the auriculars and the somewhat curved shape to the outer primaries. 


\section{NOTES}

eliminated on the basis of these same criteria, although some Marsh Warblers also show strikingly pale legs and feet.

- The Paddyfield Warbler (A. agricola), also unrecorded in North America, has a distinct pale supercilium that flares behind the eye, lacks breast streaking, and has shorter, unmarked undertail coverts.

- The Oriental Reed-Warbler (A. orientalis), unrecorded in the New World, is larger overall, has a larger bill, a distinct supercilium, and a longer tail but shorter, plainer undertail coverts.

\section{Locustella}

- Middendorff's Grasshopper-Warbler (L. ochotensis), a species that had been recorded at Gambell in fall (Lehman 2005) several times previously, and Pallas's (L. certhiola) and Styan's (L. pleskei) Grasshopper-Warblers, both of which are unrecorded in North America, have a distinct supercilium rather than merely an eye-ring, shorter and plain undertail coverts, pale tips to the tail feathers, and (in Middendorff's and especially in Pallas's) a more warmly colored rump and tail; Pallas's also has much bolder dark streaking above.

- The Lanceolated Warbler (L. lanceolata), with two previous Gambell records in fall (North American Birds 68:132), is distinctly smaller, has a different facial and undertail pattern, and has much more distinct dark streaking above and below, including on the flanks.

- Gray's Grasshopper-Warbler (L. fasciolata) is eliminated by the same criteria as the Oriental Reed-Warbler (above).

After several hours following the bird in the boneyard, we returned indoors to consult the available literature and to download our many photographs. After consulting the limited literature at hand, followed by internet-based searches of photos, I was able to rule out the Grasshopper and Savi's warblers These species breed from western Europe east to central Russia (western Siberia) and winter in Africa (Savi's) or Africa and India (Grasshopper). Savi's has a more distinct supercilium (in front of the eye), warmer but plainer undertail coverts, and the dusky spots on its upper breast are fewer and more restricted than the River Warbler's more extensive blurry streaks. Most but not all Savi's Warblers have warmer brown upperparts. The Grasshopper Warbler has obvious dark streaks or mottling on the crown, mantle, and rump and dark-centered tertials. It usually shows a more obvious, though weak, supercilium and has dark streaking restricted mostly to the lower throat and uppermost breast. Its tail appears slightly longer, with the long undertail coverts showing broad diffuse streaks rather than being pale tipped and strongly barred as in the River Warbler.

Some correspondents to whom I sent the photos also mentioned that the poorly known Chinese Bush Warbler (L. tacsanowskia), and several other species of bush warblers formerly placed in the genus Bradypterus, including the Baikal Bush Warbler (L. davidi), needed to be considered. None of these species is previously recorded in North America. The Chinese Bush Warbler and Baikal Bush Warbler, however, are long-distance migrants that breed north to the Lake Baikal region and winter in southeast Asia, so they are potential vagrants to Alaska. All of these species are smaller, less robust, and have thinner tails. Except for some Chinese Bush Warblers they have a more distinct supercilium and are typically more warmly colored above. The Chinese Bush-Warbler's long undertail coverts have a pattern of dark and light bars, as in the River Warbler, but are often warmer brown with less distinct pale tips (Kennerley and Pearson 2010). In both these species as well as the Spotted Bush Warbler ( $L$. thoracica), the undertail coverts are distinctly shorter, extending only about half way out the tail. In young Chinese Bush Warblers in autumn, the throat and belly typically are ocher or dull sulfur yellow, and the breast striations, if present, are relatively inconspicuous (P. Kennerley in litt.). 


\section{NOTES}

Kennerley, co-author of the authoritative work Reed and Bush Warblers (Kennerley and Pearson 2010), also noted that the "pale edge to the outer primary [of the Gambell bird] is unique to some [species of] Locustella, including some but not all River Warblers." He added that the Gambell bird "looks spot on for River."

The bird was never definitively identified again after 7 October.

The River Warbler at Gambell was a young bird on the basis of its pointed primaries and rectrices, and by a molt limit in the greater coverts, visible in photos (P. Pyle in litt.).

Almost all authorities refer to Locustella fluviatilis with the English name "River Warbler," but Clements et al. (2017) and www.eBird.org refer to the species as the "Eurasian River Warbler."

The River Warbler is a widespread though patchily distributed species, and it is a long-distance migrant. It breeds in damp herbaceous vegetation from Germany and Denmark north to southern Sweden and Finland and south to northern Romania, east to western Siberia in the area of Omsk on the Irtysh River at $\sim 70^{\circ} \mathrm{E}$. It winters in southeastern Africa, from northeastern South Africa north to southern Kenya (Kennerley and Pearson 2010, Birdlife International 2017). Thus the eastern limits of its breeding range in Russia, and the winter range in southern Africa, are broadly similar to those of several other species that have occurred as vagrants to western Alaska, such as the Sedge Warbler (A. schoenobaenus; Gambell, September 2007; Rosenberg and Lehman 2008), Spotted Flycatcher (Muscicapa striata; Gambell, September 2002; Lehman 2003), and, especially, the Wood Warbler (Phylloscopus sibilatrix; multiple Alaska records; Gibson and Withrow 2015, Dunn and Alderfer 2017) - as well as that of an apparent Red-backed Shrike (Lanius collurio) present at Gambell at the same time as the River Warbler (Lehman et al. unpubl. data). The Wood Warbler has occurred also twice in Korea, approximately four times in Japan, and once in Taiwan; there are single records of the Sedge Warbler for Korea and Japan (OSJ 2012, N. Moores in litt., L. Ohtsuki in litt.). By contrast, there are as yet no documented records of the River Warbler from eastern Asia (N. Moores in litt.), probably the result of the species' skulking behavior. River Warblers have occurred as vagrants at various seasons to the west of their normal range in northwestern Africa and in western Europe from Great Britain to Spain, and there are at least three records for Iceland (Kennerley and Pearson 2010).

A hearty thanks to the photographers who first flushed the bird and who worked so hard to obtain many photos: Sue Bryer, Clarence Irrigoo Jr., and Monte M. Taylor. I received invaluable input on the identification of the River Warbler from Peter Kennerley. Other helpful comments on the bird's identification were received from Jon L. Dunn, Julian Hough, Nick Lethaby, Curtis A. Marantz, Guy McCaskie, and Peter Pyle. Information on the occurrence vagrant passerines in Korea and Japan was supplied by Brian E. Daniels, Nial Moores, and Leo Ohtsuki. Suggested improvements on a draft of the manuscript were provided by Sue Bryer, Jon L. Dunn, Kimball L. Garrett, Peter Kennerley, Curtis A. Marantz, and Dan Ruthrauff.

\section{LITERATURE CITED}

BirdLife International. 2017. Species factsheet: Locustella fluviatilis; www.birdlife. org (1 December 2017).

Clements, J. F., Schulenberg, T. S., Iliff, M. J., Roberson, D., Fredericks, T. A., Sullivan, B. L., and Wood, C. L. 2017. The eBird/Clements checklist of birds of the world: version 2017; www.birds.cornell.edu/clementschecklist/download/.

Dunn, J. L., and Alderfer, J. 2017. A Field Guide to the Birds of North America, $7^{\text {th }}$ ed. Natl. Geogr. Soc., Washington, D.C.

Gibson, D. D., and Withrow, J. J. 2015. Inventory of the species and subspecies of Alaska birds, second edition. W. Birds 46:94-185. 


\section{NOTES}

Kennerley, P., and Pearson, D. 2010. Reed and Bush Warblers. Christopher Helm, London.

Lehman, P. E. 2003. Gambell, Alaska autumn 2002: First North American records of Willow Warbler (Phylloscopus trochilus), Lesser Whitethroat (Sylvia curruca), and Spotted Flycatcher (Muscicapa striata). N. Am. Birds 57:4-11.

Lehman, P. E. 2005. Fall bird migration at Gambell, St. Lawrence Island, Alaska. W. Birds 36:2-55.

Lehman, P. E., and Ake, R. L. 2011. Blyth's Reed Warbler (Acrocephalus dumetorum) at Gambell, Alaska: First record for North America. N. Am. Birds 65:4-12.

Ornithological Society of Japan [OSJ]. 2012. Check-list of Japanese Birds, $7^{\text {th }}$ rev. ed. Ornithol. Soc. Japan, Sanda, Japan.

Rosenberg, G. H., and Lehman, P. E. 2008. First North American record of Sedge Warbler (Acrocephalus schoenobaenus) at Gambell, Alaska. N. Am. Birds 62:178-181.

Accepted 13 February 2018 